\title{
O TEXTO MOSTRA A LÍNGUA, COSTURA E DESCOSTURA DISCURSOS
}

RESUMO: Neste artigo procura-se analisar a maneira como uma determinada forma da língua, transplantada de uma esfera de circulação a outra, de uma prática discursiva a outra, de uma cultura a outra, provoca o aparecimento de discursos diferenciados, os quais apontam para a riqueza da língua e sua produtividade discursiva em diferentes contextos. Apoiado nos conceitos de esfera e relações dialógicas, ambos advindos do pensamento bakhtiniano, $\mathrm{e}$ considerando que os estudos da linguagem praticados pelas diferentes vertentes da análise do discurso têm em comum o fato de tentar compreender, pela dimensão histórica, social e cultural, a produção de sentidos, este trabalho tem como objeto principal a observação dos versos de uma canção brasileira contemporânea, na qual o verbo viré utilizado em sua forma pronominal - vir-se. A observação da presença dessa forma totalmente estranha aos falantes do Português do Brasil, numa esfera artística brasileira, permite reconhecer, dentre muitas outras coisas, as formas da língua em uso como parte do objeto visado pelas análises e pelas teorias do discurso.

PALAVRAS--CHAVE: Língua; discurso; esfera; canção contemporânea.

\section{CONSIDERAÇÕES INICIAIS}

nicio este texto com uma citação de Michel Foucault, tendo por objetivo flagrar, pelo olhar desse grande filósofo, um momento fundante da maneira como o discurso e seus estudos passaram a assumir um lugar de destaque, especialmente a partir do século XX, distinguindo-se dos estudos clássicos a respeito da língua, mas sem jamais excluí-la de seu corpo de reflexões.

Pontifícia Universidade Católica de São Paulo /CNPq. 
Na obra As palavras e as coisas, uma das mais significativas de um conjunto de trabalhos inovadores sobre a linguagem, coincidentemente publicados em 1966, ${ }^{1}$ Michel Foucault identificou o discurso como objeto de estudo das Ciências Humanas, diferenciando essa perspectiva das demais formas de conhecimento da fala humana:

\begin{abstract}
(...) embora o homem seja no mundo o único ser que fala, não constitui de modo algum ciência humana o conhecer as mutações fonéticas, o parentesco das línguas, a lei das derivações semânticas; em contrapartida, poder-se-á falar de ciência humana desde que se procure definir a maneira como os indivíduos ou os grupos concebem as palavras, utilizam a sua forma e o seu sentido, compõem discursos reais, neles mostram e ocultam o que pensam, dizem, sem que talvez tenham consciência disso, mais ou menos do que pretendem dizer, deixam, em todo caso, desses pensamentos, uma massa de traços que é necessário decifrar e restituir tanto quanto é possível à sua vivacidade representativa. (Foucault [1966], p. 458-9)
\end{abstract}

As consequiências dessa perspectiva foucaultiana de linguagem são largamente conhecidas por diferentes vertentes da análise do discurso. Ainda que nem todas as análises discursivas tenham em Foucault um pólo de ancoragem, o trecho citado sinaliza, assim como tantas outras formulações feitas pelo autor, uma maneira inovadora de enfrentar a "massa de traços" verbais e extraverbais que povoa o texto e aponta para fora dele, vinculando, social e historicamente, sujeito, vida e linguagem.

Se da perspectiva teórica a obra As palavras e as coisas pode ser tomada como um dos marcos para a constituição do discurso como objeto das Ciências Humanas, a literatura, por sua vez, vem há séculos dando provas da maneira como os indivíduos ou os grupos concebem as palavras e tornam o discurso uma poderosa arma de identidade, inserção e atuação no mundo. No livro Viver para contar, Gabriel Garcia Márquez coloca a seguinte epígrafe: "A vida não é a

1 Penso aqui em Problemas de Lingüística Geral I, de E. Benveniste, em A semântica estrutural, de A. J. Greimas, e nos Ecrits, de Lacan, estudos revolucionários lançados em 1966. 
que agente viveu, e sim a que a gente recorda e como recorda para contá-la”. Esse vínculo entre vida, memória e discurso vai se explicitando a cada linha dessa autobiografia e, dentre os muitos trechos que concretizam essa ligação, há um que pode ser destacado para os interesses deste trabalho, na medida em que explicita os finos fios que articulam vida e linguagem:

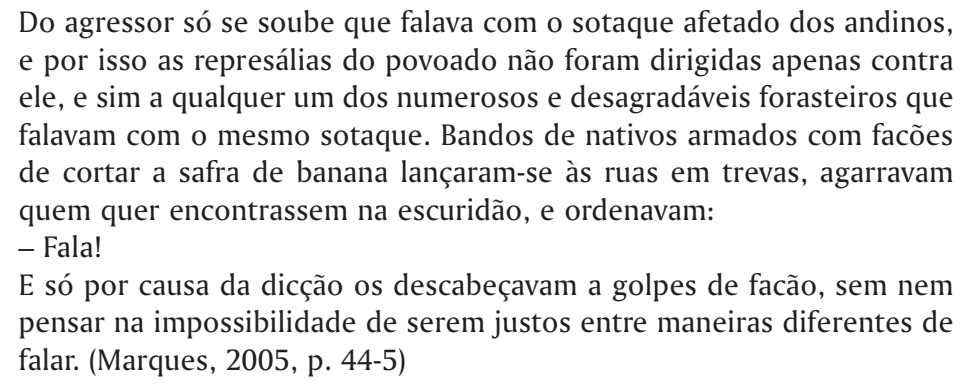

Articulando-se essa citação com a da obra As palavras e as coisas, é possível afirmar que os dois textos têm em comum o fato de explicitar a necessidade de reconhecimento da dimensão vital assumida pela linguagem tanto na atuação do homem no mundo como na sua constituição como sujeito. A variante linguiística dimensionada pelo texto de Garcia Marques funciona não apenas como um diferencial regional ou social, como seria possível analisar sociolingüisticamente, mas como conjunto de traços que contrapõe identidades, numa explícita demonstração de intolerância. Essa intolerância, que poderia ser religiosa ou política, na verdade se concretiza como intolerância linguiística, materializada na violência física que pode ser presenciada tanto nos golpes de facão, que promovem a matança, como em algumas expressões, cunhadas pelo narrador, caso de sotaque afetado e numerosos e desagradáveis forasteiros.

Essas duas expressões linguiísticas são indicativas do lugar de onde falam os sujeitos em questão, dos discursos que os atravessam e os fazem agir tão violentamente. $O$ texto traz essas expressões e elas possibilitam uma reflexão discursiva que, para se realizar como tal, terá de se apoiar no restante da narrativa e nos lugares 
históricos e sociais para os quais elas apontam. A língua em uso, nesse caso reativada pela memória de um escritor, ao mesmo tempo em que mostra também negaceia os discursos que a constituem. Cabe ao leitor, munido das conquistas teóricas, considerar essa massa de traços, decifrando e restituindo sua vivacidade representativa, conforme sugestão de Michel Foucault.

Assim, sob a perspectiva das teorias e análises do discurso, é possível surpreender discursivamente a maneira como nos textos estão constituídas, por exemplo, a força bruta, a intolerância, a desigualdade, conforme retrata Viver para contar. Mas, também, são as singulares articulações da diversidade linguiística que revelam encontros e convivências do dessemelhante e do plural, como se verá mais adiante. E é nesse sentido que a Análise do discurso participa das Ciências Humanas, tornando-se, a partir do século XX, uma área de construção de conhecimento, constituída por inúmeras e inconfundíveis vertentes. ${ }^{2}$ Sua importância, em qualquer das vertentes, reside no fato de perseguir e ressaltar as riquezas e as misérias que a linguagem encerra enquanto história, cultura, constituição, aprisionamento e libertação de sujeitos.

1. Esfera e relações dialógicas: dois conceitos centrais para o pensamento bakhtiniono

Este texto pretende destacar alguns aspectos pertinentes a uma dessas vertentes - análise/teoria dialógica do discurso ${ }^{3}$ - que, embora jamais proposta formalmente com essa designação, pode ser reconhecida ou reconstituída a partir das inegáveis contribuições para os estudos da linguagem oferecidos pelo pensamento

2 Refiro-me aqui à pluralidade de variantes abrangidas por diferentes fontes teóricometodológicas, as quais se distinguem pela "dicção", em geral reconhecidas como francesa, russa, anglo-saxônica ou, ainda, em alguns casos, como a mistura de duas ou mais diç̧ões, o que necessariamente concretiza uma nova variante.

3 As características dessa tendência foram por mim detalhadas no texto "Análise e teoria do discurso" (Brait, 2006, p. 9-32). 
bakhtiniano. Sem apresentar um conjunto de preceitos sistematicamente organizados para funcionar como perspectiva teórico/analítica fechada, as obras de Bakhtin, Voloshinov, Medvedev e outros participantes do que hoje se denomina Círculo de Bakhtin têm como embasamento constitutivo uma concepção de linguagem, de construção e produção de sentidos, necessariamente apoiada nas relações discursivas empreendidas por sujeitos historicamente situados. ${ }^{4}$ E, desde os primeiros textos aparecidos na década de 1920, ao contrário do que se fez voz corrente, esses estudos sinalizam alguns caminhos metodológicos, como se percebe nos trechos transcritos a seguir, presentes respectivamente em Problemas da poética de Dostoiévski (1929/1963/2002) e em Marxismo e filosofia da linguagem (1929/1997):

Intitulamos este capítulo "O discurso em Dostoiévski" porque temos em vista o discurso, ou seja, a língua em sua integridade concreta e viva e não a língua como objeto específico da linguiística, obtido por meio de uma abstração absolutamente legítima e necessária de alguns aspectos da vida concreta do discurso. Mas são justamente esses aspectos, abstraídos pela linguiística, os que têm importância primordial para os nossos fins. Por este motivo as nossas análises subsequientes não são linguiísticas no sentido rigoroso do termo. Podem ser situadas na metalinguística, subentendendo-a como um estudo - ainda não-constituído em disciplinas particulares definidas - daqueles aspectos da vida do discurso que ultrapassam - de modo absolutamente legítimo - os limites da linguística. As pesquisas metalinguiísticas, evidentemente, não podem ignorar a linguiística e devem aplicar os seus resultados. A linguiística e a metalinguiística estudam um mesmo fenômeno concreto, muito complexo e multifacético - o discurso, mas estudam sob diferentes aspectos e diferentes ângulos de visão. Devem completar-se mutuamente e não fundir-se. Na prática, os limites entre elas são violados com muita frequiência. (Bakhtin, 2002, p.181)

*****

A língua vive e evolui historicamente na comunicação verbal concreta, não no sistema lingüístico abstrato das formas da língua nem no psiquismo individual dos falantes.

4 Alguns aspectos teóricos e especialmente metodológicos dessa análise/teoria do discurso foram por mim destacados no texto "Uma perspectiva dialógica de teoria, método e análise" (Gragoatá, 20, p. 47-62). 
BRAIT, Beth. O texto mostra a língua, costura e descostura discursos

Disso decorre que a ordem metodológica para o estudo da língua deve ser:

1) As formas e os tipos de interação verbal em ligação com as condições concretas em que se realiza.

2) As formas das distintas enunciações, dos atos de fala isolados, em ligação estreita com a interação de que constituem os elementos, isto é, as categorias de atos de fala na vida e na criação ideológica que se prestam a uma determinação pela interação verbal.

3) A partir daí, exame das formas da língua na sua interpretação linguiística habitual (Bakhtin/Voloshinov, 1997, p. 124).

E é dentro dessa perspectiva discursiva que foi escolhido, para lançar um olhar sobre alguns textos e alguns dos discursos que neles circulam, o conceito de esfera, assim definido em Marxismo e filosofia da linguagem: ${ }^{5}$

No domínio dos signos, isto é, na esfera ideológica, existem diferenças profundas, pois este domínio é, ao mesmo tempo, o da representação, do símbolo religioso, da fórmula científica e da forma jurídica, etc. Cada campo de criatividade ideológica tem seu próprio modo de orientação para a realidade e refrata a realidade à sua própria maneira. Cada campo dispõe de sua própria função no conjunto da vida social. É seu caráter semiótico que coloca todos os fenômenos ideológicos sob a mesma definição geral. (Bakhtin/Voloshinov, 1997, p. 33)

Esse conceito, que também aparece em outras obras do Círculo, ${ }^{6}$ está necessariamente articulado à perspectiva da produção, circulação e recepção de textos e discursos e, especialmente, ao conceito de relações dialógicas. As relações dialógicas, noção central do pensamento bakhtiniano, estabelecem-se a partir das esferas discursivas e dos eventos nelas implicados. São elas que produzem os olhares, os lugares discursivos, os sentidos e, consequientemente, o conhecimento. Essas relações estão assim definidas em Problemas da poética de Dostoiévski:

5 Conferir a respeito do conceito de esfera o texto "Esfera e campo" (Grillo, 2006), In: Brait (org.), 2006.

$6 \quad$ Os demais textos em que o conceito de esfera pode ser encontrado são: La palabra en la vida y la palabra en la poesía. Hacia una poetica sociologica, de 1926, The formal method in literary scholarhip, de 1928, "A pessoa que fala no romance", de 1934/1935. 
Filol. linguiíst. port., n. 9, p. 169-183, 2007.

As relações dialógicas são irredutíveis às relações lógicas ou às concretosemânticas, que por si mesmas carecem de momento dialógico. Devem personificar-se na linguagem, tornar-se enunciados, converter-se em posições de diferentes sujeitos expressas na linguagem para que entre eles possam surgir relações dialógicas. (Bakhtin, 2002, p.183)

\title{
(...)
}

\begin{abstract}
As relações dialógicas são possíveis não apenas entre enunciações integrais (relativamente), mas o enfoque dialógico é possível a qualquer parte significante do enunciado, inclusive a uma palavra isolada, caso esta não seja interpretada como palavra impessoal da língua, mas como signo da posição semântica de um outro, como representante do enunciado de um outro, ou seja, se ouvimos nela a voz do outro. Por isso, as relações dialógicas podem penetrar no âmago do enunciado, inclusive no íntimo de uma palavra isolada se nela se chocam dialogicamente duas vozes (...). (Bakhtin, 2002, p.184)
\end{abstract}

\section{Vir-se: diferentes línguas?}

Sem insistir muito nas questões teóricas, mas procurando apreendê-las nas práticas sociais e discursivas escolhidas, é preciso reiterar o fato de que as relações dialógicas jamais são dadas de antemão. Ao contrário, são estabelecidas a partir de uma enunciação, de uma interação, de uma esfera, ou do confronto de esferas, por um enunciador, por um sujeito que as assina, envolvendo interlocutores, implicando diferenças. Não são naturais, mas estabelecidas a partir de um ponto de vista ideológico, teórico, artístico etc.

Esse é o caso dos versos transcritos a seguir.

Estou a vir

e tu como é que tens por dentro?

por que não te vens também?

Essa estrofe, colocada dessa maneira, sem qualquer assinatura, sem qualquer contexto, como que extraída aleatoriamente de um poema, grita por um contexto, por alguma coisa que possa per- 
mitir a seu destinatário apreendê-la, apropriar-se dela e conhecer alguns de seus possíveis sentidos. Talvez isso não se aplique a um falante do português de Portugal, um conhecedor das variantes lusitanas da língua portuguesa. É possível que esse destinatário tenha imediatamente identificado a significação, no sentido bakhtiniano do termo, de cada um dos versos, da sintaxe textual e discursiva que os articula e, portando, tenha atingido a significação da estrofe. Mesmo que isso tenha acontecido, certamente esse destinatário se pergunta pelo sentido, uma vez que a estrofe, desprovida de contexto e de assinatura, produz como tema um questionamento, uma interrogação, e não necessariamente um sentido possível ou efeitos possíveis de sentido.

Para os demais, que não dominam as variantes lusitanas da língua portuguesa, um aspecto linguiístico é imediatamente apreendido, resultando também numa interrogação, num questionamento. Se por um lado o uso do tu e da expressão estou a vir, em lugar de um gerúndio, remete a um conhecimento genérico e estratificado do português de Portugal, é o uso inusitado, ao menos para os brasileiros, do verbo vir, em dois dos três versos, que aponta para algum lugar e, ao mesmo tempo, para lugar nenhum: 'estou a vir', no primeiro verso; e 'por que não te vens', no terceiro. Como resolver, ainda que parcialmente esse questionamento? Que lugar é esse para onde o verbo vir aponta?

Primeiro, é preciso saber que esse conjunto de versos aparece dentro de um contexto específico: é uma das faixas do disco Cê, ${ }^{7}$ de Caetano Veloso, mais precisamente a faixa número dez, intitulada Por quê?, composta unicamente por esses três versos.

A audição de Por quê? oferece um dado a mais, em relação à leitura dos versos isolados, sinalizando uma possível interpretação ou ao menos alguns efeitos de sentido, que terão consequiências discursivas importantes. O sotaque lusitano escolhido pelo intérprete, que no caso é o próprio autor da canção, sinaliza um lugar de

Cê. Produção Universal Music dirigida por Pedro Sá e Moreno Veloso, 2006. 
vida da língua portuguesa que não é o Brasil, instaurando, no mínimo, uma dualidade de vozes, um plurilingüiismo: de um lado, a articulação letra-música, possibilitada pelas especificidades da canção enquanto texto que circula na esfera artístico-musical. De outro, um conhecido falante do português do Brasil, Caetano Veloso, simulando o falar de Portugal para interpretar a canção. É, portanto, uma canção, composta por um brasileiro, que a interpreta com sotaque de além Brasil, indicando um acontecimento discursivo constitutivo de uma "outra língua", de uma outra cultura, mas que está circulando numa esfera brasileira.

É verdade que, a partir daí, instauram-se caminhos para a busca das significações aí contidas e para alguns de seus sentidos e efeitos de sentido possíveis. E a pergunta se torna mais explícita: que prática discursiva é recuperada, é reinstalada pela letra dessa canção? Certamente, o falante da variante lusitana nem se fez essa pergunta porque compreendeu de imediato a prática discursivosocial que gerou a canção. Os brasileiros, entretanto, ainda carecem desse referente discursivo-social, que escapa inteiramente à sua vivência linguiística e cultural.

Uma saída possível é recorrer ao dicionário, esse poderoso utilitário linguiístico, para acessar significações do verbo vir flexionado, uma vez que ele não faz parte do léxico ativo dos brasileiros, mas o sotaque utilizado pelo intérprete indicia-o como componente do léxico do português lusitano. No Dicionário eletrônico Houaiss da Língua Portuguesa, como 26a . acepção do verbo vir aparece: verbo vir pron. $P$ atingir o orgasmo.

E agora fica tudo mais claro. O poeta/cancionista trouxe para os brasileiros, na perspectiva da esfera musical, a possibilidade de conhecer, por um outro ângulo, sob um novo olhar, com uma outra dimensão linguiístico-discursiva, o que na prática se conhece tão bem: atingir o orgasmo, identificado de uma forma inteiramente nova.

Se por um lado o dicionário explica a significação do verbo vir pronominal, mostrando a riqueza e as possibilidades de uma língua 
que, sendo a mesma, se desdobra em tantas outras, por outro, resta saber que discursos essa transposição de uma esfera a outra acarretou. Vale a pena prosseguir um pouco mais para saber como a busca de significações vai, também, revelar discursos que atravessam os sujeitos que entram em contato com a canção e, o que é muito importante, descortinando formas de produção de sentido ou de efeitos de sentido, explicitando, em diferentes interações, as relações língua-discursos em circulação, como pontos de vista a partir dos quais os sujeitos se revelam ou deixam revelar sua ideologia, seus valores.

A leitura de uma entrevista concedida por Caetano Veloso, mais precisamente no trecho em que fala da canção Por quê?, ajuda a exemplificar essa perspectiva. Na entrevista, o compositor-intérprete tenta explicar a significação da canção a partir de vir-se. Como se verá, ele faz curiosas observações linguiísticas, incluindo o que chama de interpretação "errônea" de um crítico que, ao ouvir o sotaque lusitano, interpretou a canção como sendo "uma piada".

Ora, a canção é séria, sobre um assunto sério e, para mim, tem mais valor por causa da observação linguiística. É que nós, brasileiros, usamos o verbo 'gozar', assim como os franceses usam 'jouir', com o significado de alcançar o orgasmo. Esses verbos se referem à curtição, à fruição do momento do orgasmo, enquanto que o equivalente inglês, 'to come', parece o ponto final de alguma coisa, assim como o espanhol 'acabar'. Mas os portugueses dão a volta por cima nessa questão, pois usam o verbo 'vir', na forma reflexiva: vir-se. A pessoa se vem. Acho isso muito bonito. E o tal crítico, só pode ter pensado que se tratava de uma piada por supor que tudo o que se fala com sotaque lusitano é uma piada. É a interpretação mais vulgar que uma canção tão invulgar pode ter encontrado (Caetano Veloso, 2006, p. 86).

Esses textos - o da canção que circula na esfera artística, o do crítico e o do autor, que circularam na esfera da mídia - auxiliam a pensar alguns aspectos da complexidade e da riqueza produzidas pelas intersecções língua, esferas de circulação, discursos circulantes.

A primeira delas é o fato de um autor, no caso um criador de canções brasileiras, portanto falante do português do Brasil, ter descoberto uma expressão característica de uma prática discursiva 
do cotidiano dos portugueses de Portugal - vir-se -, mais especificamente a maneira como o português de Portugal traduz linguiisticamente uma particularidade da relação sexual e, a partir da descoberta, ter se encantado com ela, a ponto de transportá-la para uma outra esfera, ou seja, a esfera artística em que circula a canção. Essa transposição, sem dúvida, funciona como uma forma discursiva de redirecionar o olhar cultural dos brasileiros. $\mathrm{O}$ que era discurso do cotidiano de uma fração da cultura portuguesa em condições muito marcadas, passa a discurso artístico da cultura brasileira, a partir de um deslocamento que reacentua a expressão e a coloca em outras condições sócio-históricas.

Essa passagem não se faz de maneira tranquiila e sem consequiências discursivas e avaliações por parte dos sujeitos aí envolvidos. Basta observar o estranhamento que acomete os ouvintes brasileiros da canção, levando-os, por exemplo, a consultar um dicionário da língua portuguesa. Ou, ainda, a reação do crítico, que imediatamente oferece sua versão, apoiado unicamente no sotaque lusitano praticado pelo intérprete que, para ele, é um índice de "piada". E para culminar, a necessidade de o autor construir uma explicação a posteriori. A passagem de uma expressão corriqueira da língua portuguesa praticada em Portugal, veiculada normalmente na esfera do cotidiano, para a língua portuguesa praticada no Brasil, acolhida pela esfera artístico-musical, revela não apenas a complexidade linguiística e a carga significativa da expressão, mas também a amplificação discursiva provocada pela nova esfera e as diferenciadas relações dialógicas aí instauradas.

Percebe-se, por exemplo, que ao causar estranhamento nos ouvintes e no próprio crítico, um ouvinte diferenciado, a canção apontou, mesmo antes da explicação do autor, para lugares discursivos e sócio-históricos fora dela mesma, mas não inteiramente exteriores à língua portuguesa e aos discursos em que seus falantes estão mergulhados. É como se a canção gritasse por sentido, pelo redirecionamento do olhar, do ouvido, e os interlocutores respondessem do lugar em que se situam, por meio dos discursos que os atravessam e passam a atravessar a canção. 
Esses lugares permitem encontrar, pelo ponto de vista da língua, pela esfera em que a expressão passou a circular e pelos discursos costurados e descosturados pelo uso, a maneira como duas diferentes culturas apresentam pontos de vista que criam diferentes dimensões para a, "entre aspas", "mesma prática social" e "mesma língua”. O olhar da língua, o olhar das línguas em convergência, o olhar do autor, o olhar do crítico, os diferentes olhares das línguas, recuperadas na explicação do autor, dimensionam a diferença, a variedade, o dessemelhante criado pela variedade.

Ao mesmo tempo em que, à moda de um lingüista, Caetano Veloso explica, na esfera da mídia, as diferentes maneiras como um aspecto da prática sexual é dimensionado em diferentes línguas, revelando diferentes pontos de vista culturais sobre o que imaginamos ser absolutamente idêntico para todas as culturas, ele também apresenta suas avaliações, como um mortal usuário e apreciador dos falares do mundo, deixando entrever discursos que o constituem como sujeito histórico, social, cultural. Nesse sentido, afastase do olhar de um linguiista para fazer avaliações estéticas, como cabe naturalmente a um artista. Mas nada disso ele poderia explicitar na esfera artístico-musical, sem tornar a canção um outro texto: um manifesto, talvez.

O discurso do crítico, por sua vez, está atravessado por um preconceito, como bem assinala Caetano, revelando um ponto de vista discursivo que configura um discurso corrente no Brasil sobre o falar português, estigmatizado como piada. Não importa que o crítico tenha ou não consciência do lugar discursivo que ocupa ao fazer essa interpretação. O sentido é produzido, os discursos passam a circular, vistos ou ignorados por quem profere o enunciado. São traços deixados sem que talvez [o sujeito] tenha consciência disso, como afirma Foucault.

Essa pequena canção, que não por acaso se chama Por quê?, oferece uma dimensão exemplar da produtiva complexidade que se estabelece na intersecção da plural língua portuguesa, surpreendida no diálogo entre duas esferas discursivas, que aparentemente 
apontam para uma mesma prática social. Se a prática social parece ser a mesma, na verdade as práticas discursivas que a veiculam dimensionam-na diferentemente, mobilizando diferentes sujeitos, diferentes discursos, diferentes sentidos e formas de conhecimento. Revisto na intersecção cultural promovida pela língua em diferentes esferas produção, circulação e recepção, o orgasmo passa de clímax de um ato físico a discurso, a evento discursivo.

\section{CONSIDERAÇÕES FINAIS}

Assumindo essa percepção histórica e social da língua, assim como seus usos e os traços deixados ou dissimulados nos textos, é possível compreender as inalienáveis relações existentes entre a linguagem e a vida. Se o texto mostra a língua e costura e descostura discursos, cabe à análise do discurso correr atrás dos traços de diferentes naturezas que é necessário decifrar e reconstituir. Não se trata entretanto de atingir a verdade, os verdadeiros sentidos de um texto, ou de um conjunto de textos. Muito pelo contrário. Como se procurou mostrar aqui, os sentidos produzidos por um texto, assim como os efeitos de sentido, só podem ser identificados a partir de determinados conceitos oferecidos pela fundamentação teórica que possibilita a leitura. As concepções diferenciadas de práticas discursivas, de práticas sociais, sem dúvida dependem do lugar teórico que as postula. Assim também, os conceitos de esfera e relações dialógicas têm um estatuto específico dentro do pensamento bakhtiniano, dentro do que se pode denominar análise/teoria dialógica do discurso, possibilitando um trabalho de compreensão de formas de produção de sentidos, de efeitos de sentido.

E é pelas lentes desses conceitos que um mesmo enunciado, veiculado em diferentes esferas, em diferentes culturas, torna-se outro. Que um mesmo texto, torna-se outro. 
BRAIT, Beth. O texto mostra a língua, costura e descostura discursos

\section{BIBLIOGRAFIA}

BAKHTIN, M. (2003) Estética da criação verbal. Trad. Paulo Bezerra. 4. ed São Paulo: Martins Fontes. (Original russo, 1979)

. (2002) Problemas da poética de Dostoiévski. Trad. Paulo Bezerra. 3. ed. Rio de Janeiro: Forense Universitária (original russo 1929, modificado em 1963).

. (1993) A pessoa que fala no romance. In: Questões de literatura e de estética: a teoria do romance. Trad. Aurora Fornoni Bernardini et al. 3. ed. São Paulo: UNESP/Hucitec (original russo, 1934-1935).

BAKHTIN, Mikhail M.; VOLOCHINOV, V. N. (1997) Marxismo e filosofia da linguagem. Trad. Michel Lahud e Yara F. Vieira. 8. ed. São Paulo: Hucitec (original russo, 1929).

BAKHTIN, M. M.; MEDVEDEV, P. N. (1991) The formal method in literary scholarship: a critical introduction to sociological poetics. Trad. Albert J. Wehrle. Maryland: Johns Hopkins Press (original russo, 1928).

BAJTIN, M. M.; VOLOSHINOV, V. (1997) La palabra en la vida y la palabra en la poesía. In: Hacia una filosofia Del acto ético. De los borradores. Y otros escritos. Trad. Tatiana Bubnova. Barcelona: Anthropos, p. 106-37.

BRAIT, B. (2006) Análise do discurso. In: BRAIT, B. (org.). Bakhtin: outros conceitos-chave. São Paulo: Contexto, p. 9-32.

$\overline{47-62}$.

(2006) Uma perspectiva dialógica de teoria, método e análise. Gragoatá, 20, p.

FOUCAULT, M. (s/d) As palavras e as coisas. Trad. António Ramos Rosa. Lisboa: Portugália Editora. (primeira edição Gallimard, 1966).

GRILLO, S. V. de C. (2006) Esfera e campo. In: BRAIT, B (org.) Bakhtin: outros conceitoschave. São Paulo: Contexto, p. 133-60.

MARQUES, Gabriel Garcia. (2005) Viver para contar. Trad. Eric Nepomuceno. 6. ed. Rio de Janeiro/São Paulo: Record.

VELOSO, Caetano (2006) RG VOGUE. Outubro, Edição 55, p. 86. Veloso.

(2006) Por quê? In: Cê. Produção Universal Music dirigida por Pedro Sá e Moreno

ABSTRACT: This paper seeks to analyze a language structure which, taken to a different sphere, a different discursive practice, a different culture, leads to the appearance of equally differing discourses which, in turn, point to the language assets and to its discursive productivity in different contexts. Based on the concepts of sphere and dialogical relations, both stemming from Bakhtinian terminology, and taking into account that language studies practiced by different trends of discourse analysis agree on the fact that they all seek to understand the production of meaning by means of historical, social and cultural dimensions, this paper aims, mainly, at observing the verses of a Brazilian contemporary song in which the verb vir (to come) is used in its pronominal form vir-se (also to come). Noticing the presence of this form 
Filol. lingüíst. port., n. 9, p. 169-183, 2007.

- which is totally strange to Brazilian speakers of Portuguese - in the Brazilian artistic realm, one is led to recognize the forms of language in use as part of the object targeted by analyses and by the theories of discourse.

KEYWORDS: Language; discourse; sphere; contemporary song. 